\title{
COOPERATIVE RESEARCH- ON COLLECTIVE FIELDNOTES, EXPERIENCE NEGOTIATION AND COMMON TEXT
}

\author{
ANNA GAŃKO \\ Institute of Polish Culture, Faculty of Polish Studies, Warsaw University \\ Krakowskie Przedmieście 26/28, 00-001 Warszawa \\ E-mail address: and.ganko@gmail.com \\ ORCID: https://orcid.org/0000-0001-8664-455X \\ MIKOŁAJ ŁĄTKOWSKI \\ Institute of Polish Culture, Faculty of Polish Studies, Warsaw University \\ Krakowskie Przedmieście 26/28, 00-001 Warszawa \\ E-mail address: mikolaj.latkowski@gmail.com \\ ORCID: https://orcid.org/0000-0002-9539-5361
}

\begin{abstract}
Aim. The aim is to depict the specificity of fieldnotes which as the first result of research experience stand between the perception, which obviously has to be personal (even if it is based on non-individual experience), and the text, which main feature is to be intersubjectively understandable.

Method. The study is based on the experience of conducting collaborative fieldwork and writing common fieldnotes. The paper itself is also an example of collaborative work - written together, it is an opportunity to share theoretical perspectives on team research grounded in fieldwork experience in the process.

Result. Fieldwork knowledge based on team research is created in twofold relation: towards the field itself and towards another researcher. It is not simply collecting data and confronting it with data collected by others, but it is a process of shaping pretextual knowledge and, in the next step, framing it into intersubjectively communicative form. In the case of collaborative writing, unlike that of a report, in which the final research result may be presented in the form of general conclusion, fieldnotes are much more dynamic, becoming a domain of negotiation and revealing crucial points of the collective fieldwork experience.

Conclusions. Fieldnotes as a part of the fieldwork process are the first step in translation from subjective experience to intersubjective knowledge. They have specific status as text and part of fieldwork experience at the same time, which makes them a place for connection of contradictions. They are not a step between field and writing as a separate stage of the whole process: they are part of both. They are based on what is experienced and observed in the field but they can also affect the perception of what comes next in fieldwork experience. It is a circular process: fieldnotes are not just simple results of field knowledge but a step in its development.
\end{abstract}


Journal of Education Culture and Society No. 2_2019

Key words: team research experience, collaborative fieldwork, fieldnotes, common text

\section{INTRODUCTION}

A few years ago, we made ethnographic research on public space dedicated to student's use at the main campus at the University of Warsaw. The main goal of that research was to gain knowledge about buildings of the six faculties - how they were used and what were the needs of their users. What was unusual of that project was that we decided to do this study in full cooperation - not only with regular project meetings but together in the field, in a process of analysis and in writing of summary. For us, this meant that we should cooperate even in the making of our fieldnotes.

One day we were carrying out observations in one of the University's oldest buildings when one of us realised that the space was uncomfortable because of among other things insufficient lightning. We started to discuss it and we agreed that it was an important element of the perception of that space. Later that day we were also in another academic building that was a part of our research field. Due to our prior observation, we immediately paid our attention to lightning. We once more agreed that the space there was poorly lit. After that conclusion, we spent a couple of hours in that space and made a lot of different observations about it. Darkness was a new thing we were concerned about in our study, but it was no more important than others.

Even later that day we were making fieldnotes from our field experiences in the two buildings. Initially, we made them separately one person wrote about the first building, and the other about the second one and exchanged notes afterwards. Both of us were immediately surprised about the way the other described lightning and darkness, which we talked about in the field. Simple observation that we initially agreed upon turned out to be complicated when we had to write about it. Common field experience was very different for us when we tried to describe it to the rest of our research team. We understood that we had to agree one would say "again" not only on what we saw but, even more importantly, on how to describe it to make it accurate to our experience. It commenced long hours of talk a and negotiation a related not only to rgw fieldnotes from that day but also to our whole research project.

We were together in the field and we experienced it together, we made similar observations and we agreed with each other when we talked about them. But we were still different researchers with various experiences and perspectives a fact that we could ignore in the field but not in our fieldnotes. This process of drafting a common text showed us things that lie at the root of the ethnographic study. Things that lie between the experience of the field and the text that describes and summarises it. In our case making text and especially fieldnotes showed us a process of making pre-textual knowledge that is an inseparable part of every ethnographic study. When we were making 
fieldnotes, we negotiated not only our field knowledge but, in some ways, our approach to the research area and to anthropological studies of space itself.

The hared experience of being together in the field and of writing together led us to the reflections presented in this paper. Most of our observations presented here are based on our own experience of making fieldnotes. We were making them collectively and collaboratively, so that experience of joint observation is not framed in words of only one.

Our collective writing had different forms. Usually, we worked on drafts made by one of us. Sometimes the whole topic was divided into parts and we worked on our drafts separately. After that the other read the draft and added whatever in his or her opinion was missing, sometimes asked questions and added comments that should be discussed in order to agree on the final shape of the text. Those parts were especially revised, rearranged or even completely changed. Usually, this part of our collective writing was the most fruitful but sometimes simultaneously the most frustrating part of our writing.

This article was written in a similar way. There is no single main author or editor, both are equally engaged and included, so that even though it is one text in which we are trying to speak together, this authors' double-voice can be traced in some interpretation nuances, instability of style, and especially in writing subject gender, which is intentionally mixed in this article. We use both forms, he or she alternately, in order to refer to the figure of the researcher in this essay. Since the researcher is embodied, they are also gendered, which is not without significance given fieldwork experience. In the case of our fieldnotes as well as this paper, when writing it together without divided sections prepared separately, we wanted to keep this duality as an important aspect of our research and writing. Hence when we consider a researcher also in a theoretic, general way (not giving examples of our experience), we did not want to create a solely male or female figure.

\section{REFLECTION}

Collaboration proposed and practised by us was based on the strict cooperation in the field co-being in the experience of studied space. But the field is inseparable from fieldnotes, as Tomasz Rakowski says, as well as fieldnotes are intrinsic parts of a text that summarises the whole study. Each ethnographic study is bound by field experiences, which are named by Rakowski a pre-textual knowledge. According to Rakowski, it is "active, embodied formation of knowledge shaped in the form of a series of recognitions that are filling in the experience of acquiring field knowledge" (Rakowski, 2018, p. 17). This knowledge is always under the influence of prior research experiences of a practising scholar which undergoes a process of localisation in the new study area.

That knowledge clashes with new experiences. It is reshaped, customised and built upon to be accurate to the local situations that need to be understood on their own rudiments. As Ryszard Nycz argues, this process is one of the most impor- 
tant in ethnography as a whole because it changes the order of gaining and presenting field knowledge: it should always start at the bottom, which in this case is as close to the living people and their practices as possible (Nycz, 2018, p. 12).

But, as one of us has already stated in a different text, the process of gathering field knowledge is always shaped by upcoming text the summary of the whole study, which is in most cases the main goal of research practices (Gańko, 2018). Field research almost always starts with experiences that are slowly shaped by the researcher and her perspective, knowledge and embodied recognition. Simon Ottenberg argues that at this stage of study an anthropologist makes headnotes, which he describes as a record of mental notes (Ottenberg, 1990). They are the first step to organising field experience and knowledge. They are made without paper one would say only in the head of a researcher but they shape the research process in a significant way. They are a way of negotiating knowledge between the anthropologist and the field. Yet they are the first step on the road to textualising ethnographic knowledge.

Next come fieldnotes, which can be described as texts before the main text. Laurel Richardson notices that the usual way of writing an ethnographic text is to start when you know what you want to write (Richardson, 2014). Fieldnotes could not be further from that. They are an inherent part of the research process; even further, they are inseparable from fieldwork. They should describe experiences and events that occurred during parts of the study. They are meant to communicate observations as they happened so they should be created on a day-to-day basis. If there are interpretations in them, they are simplistic and preliminary, they are not analyses that take into consideration the whole research material. For these reasons, fieldnotes can be fragmentary and incoherent.

Fieldnotes are a part of fieldwork not only as an evidence or a testimony. They are an active part of the study because they are the first step on the road to textualised experiences and observations of a researcher. This is an extremely important step but, at the same time, a move that brings us not far from the field. We can go back to our fieldnotes and try to understand the problem of study from the new perspectives that we noted in these texts. As Laurel Richardson describes it, these texts can be a path of ethnographic study (Richardson, 2014). Fieldnotes, of course, are related to the main text a report or paper that summarises the whole study but in this relation, they are used more like stable texts. Then they are perceived as sources and testimonies that should be collected and summarised.

The situation gets much more complicated when research is conducted by more than one person and, what comes further, researchers are not exchanging fieldnotes but preparing them together. The first part of the path described above is not a straight line, it rather goes in circles that engage fieldwork and fieldnotes, experiences, pre-textual knowledge and first texts. Each of these features of ethnographic work is somehow connected to each other and each of them involves many topics that are working together in every study. After the first day in the field and after drafting the earliest fieldnotes, these features become inseparable in the research process. But as the linear text requires, we have to start at the beginning, where every ethnographic undertaking should begin, namely in the field. 
Fieldwork experience (like any other experience) is simultaneously individual and specific, unique and holistic in a context of the perceived phenomena. It is unique and specific, hence it cannot be replaced by any other experience or any other kind of knowledge. It is individual and because of that, it is never identical to someone else's experience. It refers to the whole of the experienced reality during fieldwork, it is impossible for a researcher to focus only on the topic he or she assumed as the main one, the chosen topic is always seen as a part of the wider context. And finally, the fact that the experience is in a way comprehensive does not paradoxically mean that it is the only possible experience and that it is so complete in its meaning that nothing can be included. Of course, there some new facts can always possibly emerge, and so can new observations but this incompleteness is revealed mostly when two different and irreducible perspectives connect. That is what happens when the research is conducted by more than one person and it is especially visible in the situation of collaborative writing of fieldnotes.

When explaining Ottenberg's term of a headnote, Roger Sanjek writes that it "identifies something immediately understandable to ethnographers" (Sanjek, 1990, p. 93). To be precise we should say: to each ethnographer. Headnotes belong to the pre-textual part of the research and they are more about understanding than explaining; due to this fact, they are impossible to share. Sanjek continues indicating processual character of knowledge based on fieldwork, which evolves with the fieldwork experience, with the following words: "We come back from the field with fieldnotes and headnotes. The fieldnotes stay the same, written down on paper, but the headnotes continue to evolve and change as they did during the time in the field" (Sanjek, 1990, p. 93). He concludes writing that "Ethnography, Ottenberg explains, is a product of the two sets of notes. The headnotes are more important. Only after the anthropologist is dead are the fieldnotes primary" (Sanjek, 1990, p. 93). It is difficult not to agree with Sanjek that headnotes are primary for fieldnotes since one is based on the other.

However, it might be fruitful not to simply compare the content of both, headnotes and fieldnotes, since they are qualitatively different, but to take a closer look at what is happening when they are taken together. If fieldnotes were considered a descriptive framework of pre-textual knowledge, they would be recognised as an intersubjectively communicative form thereof. Of course, that way reducing and transforming them in accordance to the requirements of the medium is unavoidable. Although even including that, it opens one new and crucial possibility, namely they can be compared to each other. It opens the field to more systematic sharing perspectives and exchanging knowledge based on fieldwork experience. When headnotes can be somehow shared in a discussion, fieldnotes can be compared and meticulously compared.

Writing fieldnotes in collaboration with another researcher regarded as a procedure of sharing fieldwork knowledge and fieldwork perspectives in concern of coherency could not be an additive process. Another researcher except of supplements to a primary note is also giving his doubts and questions that can completely change the final result. Very often these point out interesting 
points in the research. aspects which are not obvious. It creates the possibility to take a closer look at them and to realise their complexity.

Even though every fieldwork experience, hence fieldwork knowledge, is irreplaceable (not only it is a part possible to express but it is also regarded as the ability to recognise and understand important phenomena in the field (Rakowski, 2014), it does not mean that it cannot be shaped. It changes in contact with the field as vividly experienced reality as well as in contact with another researcher and knowledge expressed by him in her actions and especially in the situation considered in his word.

In his cooking metaphor, James Clifford compares research writing to cooking ingredients. For Clifford, inscriptions are notes taken not raw but slightly cooked or chopped prior to cooking. In the next step, description are notes sauteed and ready for later addition of theoretical sauces. In the end, transcriptions are seen as reheated leftovers (Clifford, 1990, p. 58). If we push this metaphor further and say that ingredients of each researcher are specific of their kind, we can conclude that putting together ingredients of two can give the taste impossible to create by one; it can change the whole mixture, rearrange the whole knowledge and put it on another level.

Firstly, regarding team research, field knowledge is created in twofold relation. It emerges primarily in relation to the field. It is based on the researcher's perspective stemming from the observation and it should include the perspective of other actors in the field. Secondly, field knowledge is shaped while confronting fieldwork experience and knowledge of one researcher with another. What is more, since both the field itself (including phenomena, actors with their actions) and the co-researcher are active and responsive, such knowledge must be described as processual. It is not simply collecting data and confronting it with data collected by others. Since fieldwork experience (as an experience of surrounding reality) is comprehensive, confronting it with another's fieldwork experience cannot be seen as an additive mechanism. It is rather sharing understanding and since a researcher's task is to find the most adequate description of phenomena investigated, the whole process of sharing the experience, thus sharing the knowledge, becomes the process of negotiation on what we are able to agree in writing.

Presenting fieldwork results in an academic way means putting comprehensive, pre-textual field knowledge into an intersubjectively communicative, linear, written form, which requires specific efforts and implies struggling with language matter. This struggle is especially present when it comes to collective writing in order to be close to the field. In many cases, it is not an easy task for researcherswriters to agree even on a simple description, even though they both agreed before on their conclusions. This is what happened to us in the story cited as the opening of this paper. This example clearly reveals the basic but crucial feature of the language, easily traced in its written form: language medium is not transparent, thus it is not innocent (Ong, 1982). Writing fieldnotes, especially in a collaborative scheme, very often results in struggling with words which seem to resist and which are unable to express the wide variety of aspects established in pretextual knowledge. 
That is why our experience of collective writing is commonly connected with arguments about words: sometimes it is a discussion about whole statements, sometimes it is just one descriptive expression, sometimes one particular word. In many cases, even though it seemed to be useless, taking to much time and taking our attention from what is most important from the field revealed itself later on to be the starting point to finding the meaning that could be easily omitted without that process. In our case, the story opening the paper, the topic of lighting in connection with other features related to sensual reception of the space, was one of the most important elements in understanding its functioning in the practices of its users.

As Nicholas H. Wolfinger (2002) notices, "we cathect our notes - they become part of us. Therefore it is important to understand the processes underlying their creation and how these processes can affect ethnographic texts" (p. 92). It should be equally important how these processes can affect the understanding of what is happening in the field - the ability to notice and understand certain aspects of upcoming observation. What is important here is the fact that fieldnotes have a specific status as a text and a part of fieldwork experience at the same time. They are in between parts of the research which are qualitatively different, which makes them place for connection of contradictions. What is more, they are not a step between field and writing as a separate stage of the whole process: they are part of both. Of course, they are based on what is experienced and observed in the field but they can also affect the perception of what comes next in fieldwork experience. It is a circular process: fieldnotes are not just simple results of field knowledge but a step in its development.

\section{REFERENCES}

1. Clifford, J. (1990). Notes on (Field)notes. In: R. Sanjek (Ed.), Fieldnotes. The Makings of Anthropology (pp. 46-71). Ithaca and London: Cornell University Press.

2. Gańko, A. (2018). Writing what is told - on ethnographic narrative and text. Journal of Education Culture and Society, 2, 229-237.

3. Hammersley, M., \& Atkinson, P. (1995-2007). Ethnography: Principles in Practice. New York, NY: Routledge.

4. Nycz, R. (2018). Odkrywanie zmysłu działania [Discovering the sense of action]. Teksty drugie 1, 7-15.

5. Ong, W. J. (1982). Orality and Literacy: Technologizing the word. London, New York: Methuen.

6. Ottenberg, S. (1990). Thirty Years of Fieldnotes: Changing Relationships to the Text. In: R. Sanjek (Ed.), Fieldnotes. The makings of Anthropology (pp. 138-161). Ithaca and London: Cornell University Press.

7. Rakowski, T. (2016). Hunters, Gatherers, and Practitioners of Powerlessness. An Ethnography of the Degraded in Postsocialist Poland. Oxford: Berghahn Books.

8. Rakowski, T. (2018). Etnografia przedtekstowa. Fenomenologiczne korzenie interpretacji antropologicznej [Pretextual Ethnography: The Phenomenological Roots of Anthropological Interpretation]. Teksty drugie, 1, 16-39.

9. Richardson, L. (2014). Pisanie jako metoda badawcza [Writing as a research method]. In: N. Denzin, Y. Lincoln (Ed.), Metody badań jakościowych (pp. 457-482). Warszawa PWN.

10. Sanjek, R. (1990). A Vocabulary for Fieldnotes. In: R. Sanjek (Ed.), Fieldnotes. The Makings of Anthropology (92-138.). Ithaca and London: Cornell University Press.

11. Van Maanen, J. (1988). Tales of the Field: On Writing Ethnography. Chicago: University of Chicago Press.

12. Wolfinger, N. H. (2002). On writing fieldnotes: collection strategies and background expectancies. In: D. Silverman (Ed.), Qualitative research. London: SAGE Publications. 